\title{
Enhanced Expression of Tissue Inhibitor of Metalloproteinases-4 Gene in Human Osteoarthritic Synovial Membranes and Its Differential Regulation by Cytokines in Chondrocytes
}

\author{
Wensheng Huang, Mohammed El Mabrouk, Judith Sylvester, Faramaze Dehnade and \\ Muhammad Zafarullah*
}

\begin{abstract}
Department of Medicine, University of Montreal and Research Center of CHUM (CRCHUM) Notre-Dame Hospital, Montreal, Quebec, H2L 4M1, Canada
\end{abstract}

\begin{abstract}
Objective: Tissue inhibitors of metalloproteinases (TIMPs) are multi-functional proteins with matrix metalloproteinases-inhibiting activities. We studied expression of anti-inflammatory, TIMP-4 gene in human joint tissues and its regulation by arthritis-associated cytokines.

Results: TIMP-4 RNA expression originating from synovial fibroblasts was significantly $(2.4$ fold; $<<0.001)$ elevated in 8 osteoarthritic (OA) versus 7 non-arthritic synovial membranes. Non-arthritic and OA femoral head and knee chondrocytes displayed substantial but variably constitutive expression of the TIMP-4 mRNA. In articular chondrocytes, transforming growth factor beta (TGF- $\beta 1$ ) and oncostatin M (OSM) upregulated TIMP-4 RNA and protein expression while interleukin-1 (IL-1 $\beta$ ) and tumor necrosis factor alpha (TNF- $\alpha$ ) did not, suggesting differential regulation by arthritisassociated cytokines. Interleukin 17 (IL-17) mildly induced TIMP-4 mRNA. TGF- $\beta 1$ induction of TIMP-4 expression was partly inhibited by ERK pathway and Sp1 transcription factor inhibitors.

Conclusion: Enhanced TIMP-4 gene expression in OA synovial membranes and cartilage may be due to induction by TGF- $\beta 1$, OSM and IL-17, suggesting its pathophysiological role in tissue remodeling in human joints. TGF- $\beta 1$ induction of TIMP-4 expression is mediated partly by ERK pathway and Sp1 transcription factor.
\end{abstract}

Keywords: Osteoarthritis, synovium, chondrocytes, TIMP-4, cytokines.

\section{INTRODUCTION}

The TIMP gene family consists of four members, which have matrix metalloproteinases (MMPs)-inhibiting, antiangiogenic, growth-promoting and proapoptotic activities in diverse systems [1]. TIMP-4 inhibits endothelial cell migration but does not block angiogenesis and may have distinct properties [2]. Abilities of TIMPs (particularly TIMP-3) to inhibit MMPs, ADAMTS-4/5 (aggrecanases) and tumor necrosis factor (TNF- $\alpha$ ) converting enzyme (TACE/ADAM17) can potentially reduce joint inflammation and cartilage resorption in arthritis [3]. TIMP-3 and TIMP-1 overexpressing synovial fibroblasts have reduced capacity to invade cartilage in SCID mouse model [4]. TIMP-4 is expressed in human heart and certain other tissues [5]. TIMP-4 inhibits major MMPs including MMP-13 implicated in arthritic tissue damage [6]. TIMP-4 associates with MMP2/MT1-MMP complex but its knockout had no effect on MMP-2 activation [7]. Since TIMPs-MMPs/ADAMTS balance is critical for cartilage integrity, understanding the patterns of TIMP family expression and regulation in joints is of profound importance. MMP-3, TIMP- 1 and TIMP-3 mRNA is increased in human OA synovium and articular chondrocytes express TIMP-1, TIMP-2 and TIMP-3 genes

*Address correspondence to this author at the K-5255 Mailloux, Hôpital Notre-Dame du CHUM, 1560 Sherbrooke est, Montréal, Québec, H2L 4M1, Canada; Tel: 1-514-890-8000, Ext. 25690; Fax: 1-514-412-7612;

E-mail: Muhammad.Zafarullah@UMontreal.ca
[8]. TIMP-4 gene therapy diminished experimental arthritis and periodontitis in rats, suggesting an association between the two inflammatory diseases and therapeutic potential of TIMP-4 [9, 10]. Besides reported lack of expression in synovial fibroblasts [11], information about the TIMP-4 expression in human joints is scant. We previously showed an increased TIMP-4 expression in femoral head cartilage of OA patients as a possible remodeling response, however, stimulating factors are unknown [12]. Synovial membrane is an important protective tissue around cartilage, which could become inflamed and hyperplasic during rheumatoid arthritis and could invade cartilage, leading to its destruction [13, 14]. Here we investigated whether TIMP-4 RNA is expressed in human non-arthritic and OA synovial membranes and if its expression is regulated by arthritis-related cytokines in chondrocytes.

\section{MATERIALS AND METHODS}

\section{Patients, Tissues and Cell Culture}

Synovial membranes from 7 non-arthritic, post-mortem ( 3 female and 4 male, mean age 53.6 years) tissues with no knee joint disease were analyzed. Knee OA synovial membranes were from eight patients ( 4 female and 4 male, mean age 71.3 years) with clinically and radiologically defined knee OA and were obtained after total knee replacement surgery. For TIMP-4 gene expression in human knee (patient data not available) and femoral head cartilage (non-arthritic hip fractures, 2 females, mean age, 83 years; 
hip late-stage OA, 9 female and 6 male, mean age 72.1 years; osteophytes excluded), chondrocytes were released after digestion with pronase $(1 \mathrm{mg} / \mathrm{ml})$ for $1 \mathrm{~h}$ followed by collagenase $\left(2 \mathrm{mg} / \mathrm{ml}\right.$, Sigma type-II) for $8 \mathrm{~h}$ at $37^{\circ} \mathrm{C}$ with agitation, grown for one week in DMEM supplemented with 1X penicillin-streptomycin solution and $10 \%$ fetal calf serum as primary cultures, maintained in the same medium without serum for $24 \mathrm{~h}$ and RNA extracted. Synovial fibroblasts were obtained by mincing and digestion of non-OA or OA synovial membranes with $0.25 \%$ trypsin and $2 \mathrm{mg} / \mathrm{ml}$ collagenase, passing through strainer, culturing adherent cells and removal of non-adherent cells. Synovial fibroblasts at passage 3 were kept in $0.5 \%$ serum for $24 \mathrm{~h}$ before RNA extraction. For cytokine treatments, high-density passage 2 knee chondrocytes (Cambrex) were grown to confluence, kept in serum-free medium for $36 \mathrm{~h}$ and treated with TGF- $\beta 1$ $(10 \mathrm{ng} / \mathrm{ml})$, OSM $(25 \mathrm{ng} / \mathrm{ml})$, TNF- $\alpha(20 \mathrm{ng} / \mathrm{ml}), \mathrm{IL}-1 \beta(10$ $\mathrm{ng} / \mathrm{ml}$ ) and IL-17 (20 ng/ml) (all from R\&D Systems) for 24 $h$ and RNA and protein extracted. In some cases, chondrocytes in serum-free medium were pretreated with MEK inhibitor, U0126 (Calbiochem) or Sp1 inhibitor, mithramycin (Sigma-Aldrich) for $30 \mathrm{~min}$ and then induced with TGF- $\beta 1$ for $24 \mathrm{~h}$ and total RNA analyzed for TIMP-4 and GAPDH expression by RT-PCR. The tissues used in this study were obtained either during autopsy (after $12 \mathrm{~h}$ of death due to cardiocerebral events) or during knee/hip replacement surgery at Hopital Notre-Dame du CHUM with the consent of patients or families and with the approval of Comité d'éthique de la recherche du Centre hospitalier de l'université de Montréal (CHUM) protocole number ND98.58 entitled "Base moléculaire de regulation des genes d'inhibiteurs tissulaire des métalloprotéinases-3 (TIMP-3) et (TIMP-4) par les facteures de croissance et antioxydants dans les cellules de tissues conjonctifs". The research project conformed to the Helsinki declaration and local ethics committee regulations.

\section{RNA Extraction and RT-PCR}

RNA from human knee synovial membranes was extracted by homogenization in guanidinium isothiocyanate solution and cesium chloride ultracentrifugation, quantified and its integrity verified by gel electrophoresis as described [8]. Total RNA from primary cultures was isolated by the acid guanidinium thiocyanate-phenol-chloroform method [15].

For RT-PCR, $2 \mu \mathrm{g}$ RNA was heated for $5 \mathrm{~min}$ at $65^{\circ} \mathrm{C}$ and reverse transcribed in the reaction mixture consisting of oligo d (T) 12-18mer, dNTPs, RNase inhibitor (AmershamPharmacia), acetylated BSA with reverse transcriptase (MMLV-RT) (Invitrogen) according to Clontech (Paolo Alto, CA) protocols. Aliquots of $5 \mu$ were subjected to PCR with TIMP-4 or GAPDH primers. The forward and reverse primers specific for human TIMP-4 cDNA [5] were: 5'-AGA CCT CAC AGG CTC AGT CG-3' and 5'-CAT TCC TGC CAG TCA GCC TG-3' respectively. The amplification profile was one cycle of $94^{\circ} \mathrm{C}$ for one min (hot start), 35 cycles of $94^{\circ} \mathrm{C}$ for one min, hybridization at $60^{\circ} \mathrm{C}$ for $2 \mathrm{~min}$ and extension at $72^{\circ} \mathrm{C}$ for $3 \mathrm{~min}$. A final extension cycle of 7 min at $72^{\circ} \mathrm{C}$ was also included. The amplifications were performed in the GeneE cycler (Techne, England) in a $50 \mu 1$ reaction with $1.25 \mathrm{mM}$ dNTPs, Taq DNA polymerase (Pharmacia) and respective primers. The GAPDH cDNA amplification kit and primers were from Maxime Biotech. Inc. (South San Francisco, CA). Aliquots $(10 \mu 1)$ were analyzed on 1.2 (TIMP-4) or 1.4 (GAPDH) \% agarose gels to detect TIMP-4 and GAPDH amplicons of 1148 and 226 bp respectively. Negative controls included either RT-PCR reagents except cDNA or, RT minus reactions. None of them gave any bands. The TIMP-4 cDNA was cloned in pGEM$4 \mathrm{Z}$ and its identity confirmed by comparison with the reported DNA sequence [5].

TIMP-4 cDNA band intensities were quantified by NIH ImageJ $1.32 \mathrm{j}$ (National Institute of Health, USA) software and divided by those of GAPDH. Results are reported as means \pm SEM of at least 3 different experiments and were compared with Prism software by student's t test or ANOVA, followed by a Newman-Keuls multiple comparison. $\mathrm{p}$ $<0.05$ was considered significant.

\section{Western Blotting}

Total cellular proteins $(20 \mu \mathrm{g} / \mathrm{lane})$ were separated by SDS-PAGE and blots reacted with rabbit Anti-carboxy terminus human TIMP-4 polyclonal antibody (Chemicon AB816) that detects a $29-\mathrm{kDa}$ band, which co-migrates with the purified human TIMP-4 protein.

\section{RESULTS}

\section{TIMP-4 Expression in Human Synovial Membranes}

Ability of human synovium to express the newest TIMP4 gene was investigated. RT-PCR analysis of RNA from 7 control and 8 knee OA patients revealed that both categories of subjects expressed TIMP-4 mRNA. One normal and one OA synovium had lower but detectable levels of TIMP-4 mRNA relative to the other samples. Cloning and DNA sequencing of the PCR product at both ends confirmed its identity as TIMP-4 cDNA. The control GAPDH mRNA levels remained consistent (Fig. 1A). Quantitative analysis of the bands revealed a statistically significant $(p<0.001) 2.4$ fold enhancement of TIMP-4 expression in OA patients (Fig. 1B). TIMP-4 expression in the tissues originated partly from synovial fibroblasts as 5 separate synovial fibroblast cell lines expressed TIMP-4 mRNA (Fig. 1C).

\section{TIMP-4 Expression in Human Hip and Knee Chondrocytes}

To examine if human hip joint chondrocytes expressed TIMP-4 gene ex vivo, RNAs from the quiescent chondrocytes of two older patients with femoral fracture and 15 patients with hip OA were analyzed. All specimens expressed variable but clearly detectable levels of TIMP-4 mRNA along with consistent GAPDH control mRNAs. Determination of TIMP-4/GAPDH ratio revealed an increased tendency of TIMP-4 expression (though not statistically significant) in hip OA chondrocytes (Fig. 2A). Chondrocytes from 6 normal human knees also expressed TIMP-4 RNA but its expression in OA chondrocytes was variable Nevertheless, calculation of TIMP-4/GAPDH ratio revealed a decreased tendency (not statistically significant) of TIMP-4 expression in knee OA chondrocytes (Fig. 2B). 

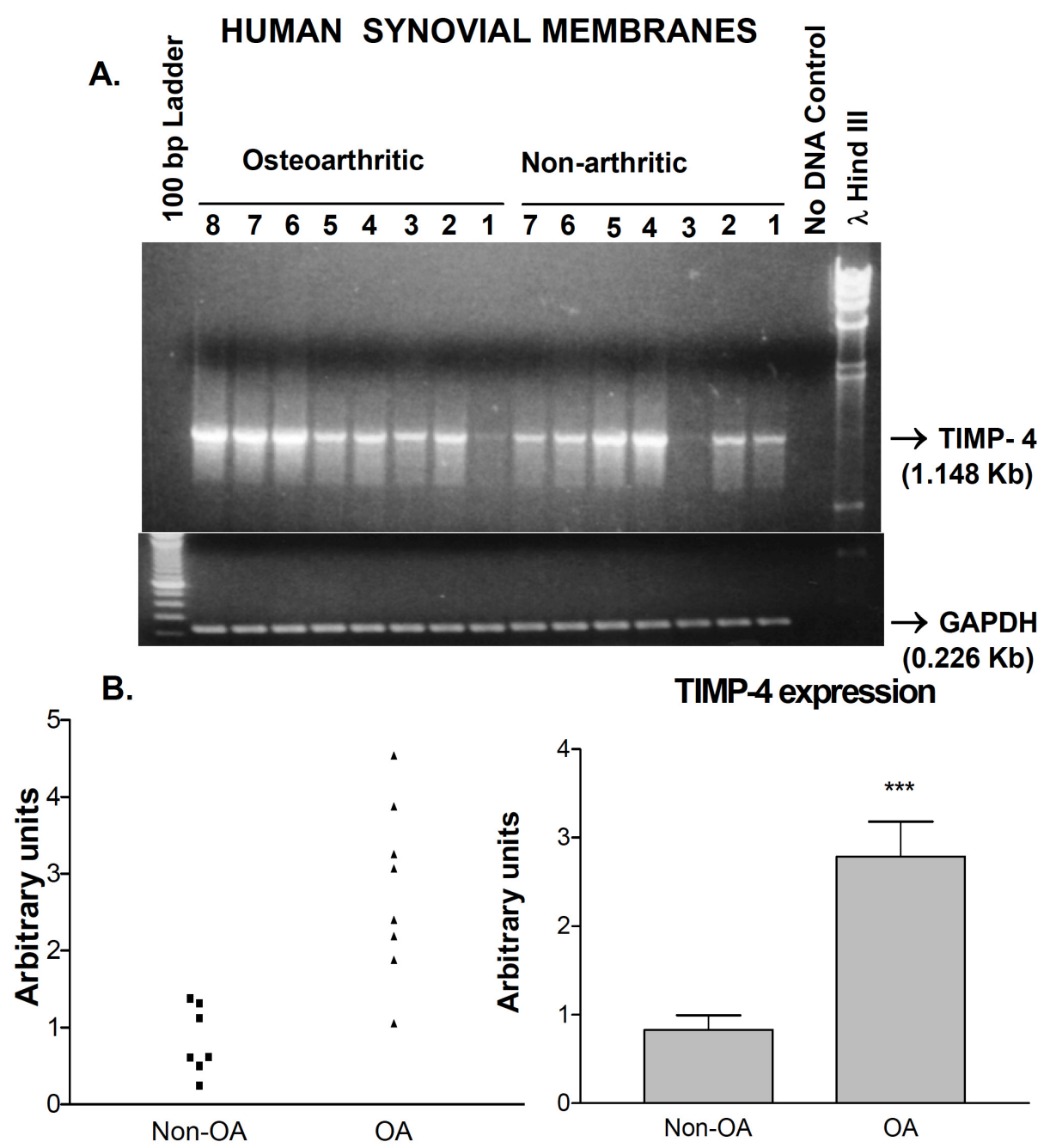

C.

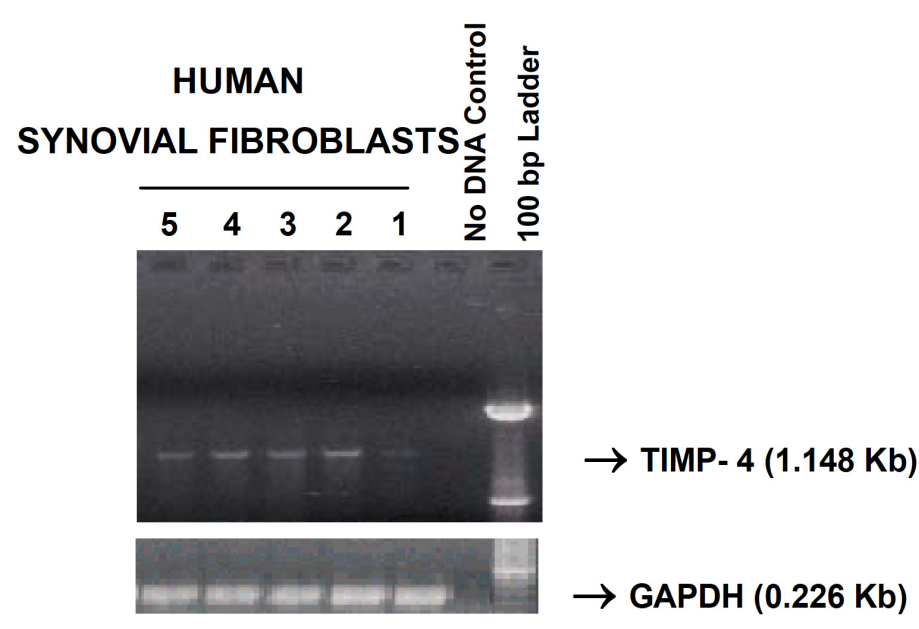

Fig. (1). A) Expression of the TIMP-4 gene in human synovial membranes from non-arthritic and osteoarthritic patients. The specific amplification of TIMP-4 and GAPDH fragments (arrows) along with the lambda Hind III or 100 bp ladder markers is shown. 'No DNA' control lane represents PCR reactions with primers but without cDNA. B) Middle panels show two graphic representations of semiquantitative analysis of TIMP-4 RNA bands. *** $\mathrm{p}<0.001$ Non-osteoarthritic (non-OA) versus osteoarthritic (OA). C) TIMP-4 RNA is expressed in non-OA (lane 1, 4, 5) and OA (lane 2, 3) synovial fibroblast lines from different patients.

\section{Impact of Cytokines on TIMP-4 Expression in Human Chondrocytes}

To identify the possible stimuli responsible for TIMP-4 increase in joints (this work and [12]), we investigated the previously unreported TIMP-4 regulation by the cytokines and growth factors found elevated in arthritic joints [16]. Treatment of normal human knee chondrocytes with TGF$\beta 1$, OSM, TNF- $\alpha$, IL- $1 \beta$ and IL-17 (at doses known to induce MMPs or other TIMPs) for $24 \mathrm{~h}$ revealed that TGF- 


\section{A. PRIMARY HUMAN FEMORAL HEAD CHONDROCYTES}

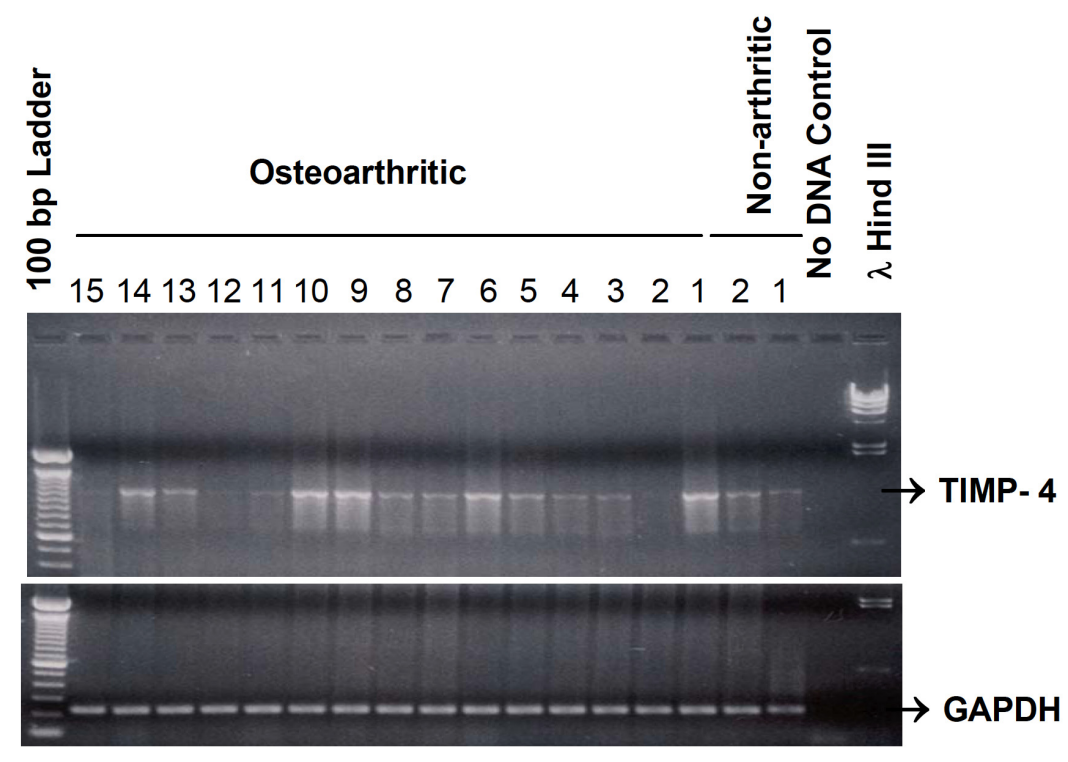

\section{B. PRIMARY HUMAN KNEE CHONDROCYTES}

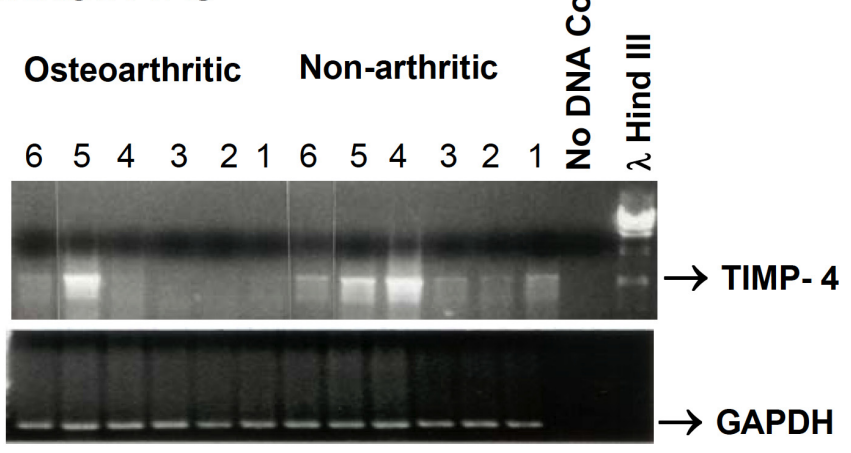

\section{Femoral head TIMP-4 expression}
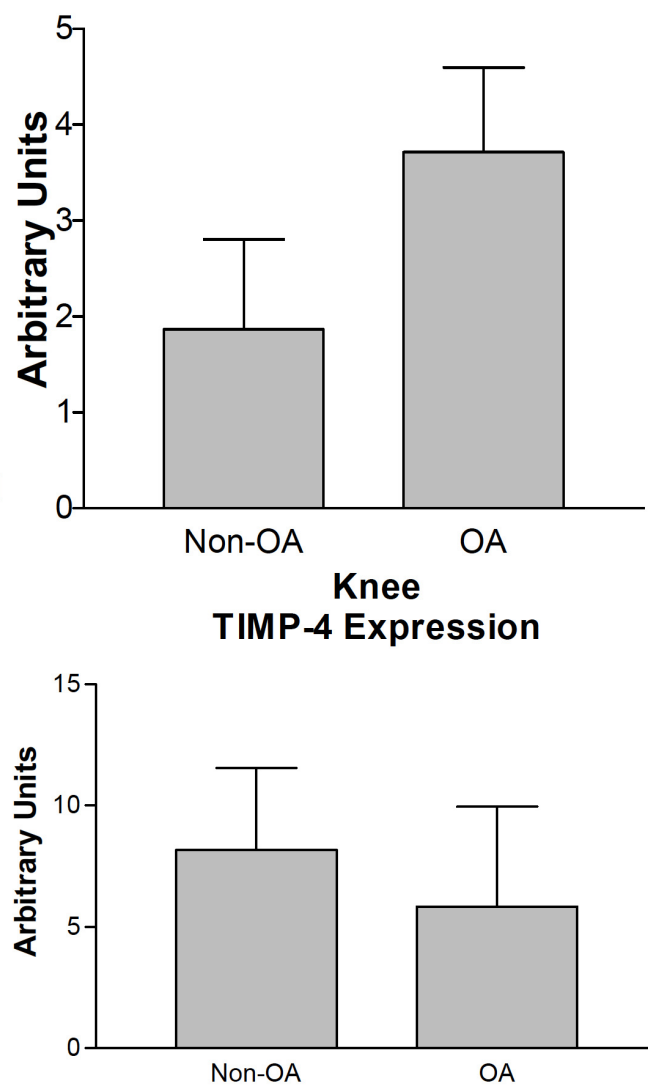

Fig. (2). A) Expression of the TIMP-4 mRNA in primary human non-arthritic and OA femoral head articular chondrocytes. All conditions were same as in Figure 1. The right panel is a cumulative graphic depiction of mean \pm SEM TIMP-4/GAPDH ratios indicating TIMP-4 increase in hip OA chondrocytes. B) TIMP-4 RNA expression by RT-PCR analysis in knee chondrocytes from six non-OA and 6 OA patients with negative control (no DNA) and markers. The right panel is a cumulative graphic depiction of mean \pm SEM TIMP-4/GAPDH ratios indicating TIMP-4 decrease in knee OA chondrocytes.

$\beta 1$, OSM and IL-17 moderately (0.5-1 fold) up-regulated while IL- $1 \beta$ and TNF- $\alpha$ did not induce TIMP-4 RNA. A similar pattern of induction was observed at the protein level (Fig. 3).

\section{Mechanism of TIMP-4 Induction by TGF- $\beta 1$}

Since TGF- $\beta 1$ induces TIMP-3 gene regulation through activation of extracellular-signal-regulated kinase (ERK) pathway and Sp1 [17], we investigated whether TIMP-4 is regulated by such a mechanism. TGF- $\beta 1$ induced TIMP-4 mRNA and MEK inhibitor, U0126 treatment, partially suppressed this induction (Fig. 4A, left panel). Similar inhibition by U016 was observed when TIMP-4/GAPDH ratios from three independent experiments were determined (Fig. 4A, right panel). Similarly, Spl transcription factor inhibitor, mithramycin almost completely suppressed TIMP4 induction (Fig. 4B, left panel). Determination of TIMP4/GAPDH ratios from two independent experiments revealed TIMP-4 inhibition by mithramycin (Fig. 4B, left panel). Although statistically non-significant, these results suggest that ERK pathway and Sp1 factor are important mediators of TIMP-4 induction by TGF- $\beta 1$.

\section{DISCUSSION}

Increase in TIMP-4 mRNA levels in OA synovial membranes suggests a pattern analogous to that of TIMP-1 and TIMP-3, which may possibly be to counteract excessive MMP-driven destruction [8]. Indeed, MMP-1, MMP-3 and MMP-13 are increased in pannus-like tissue in advanced OA [18]. Furthermore, synovitis has been observed in knees of patients with OA [19]. TIMP-4 increase by gene therapy is known to reduce levels of proinflammatory cytokines, IL-1 and TNF- $\alpha$ [9]. Previously reported lack of TIMP-4 expression in immortalized synovial fibroblasts [11] may be due to lower sensitivity of RNAse protection assay compared to the more sensitive RT-PCR technique used here. Our results clearly demonstrate synovial fibroblast as one of the cell-types that contributes to the observed expression in the tissue. It is possible that inflammatory cells in joints also express TIMP4 as observed in atherosclerotic tissue inflammation [20]. 
HUMAN KNEE CHONDROCYTES
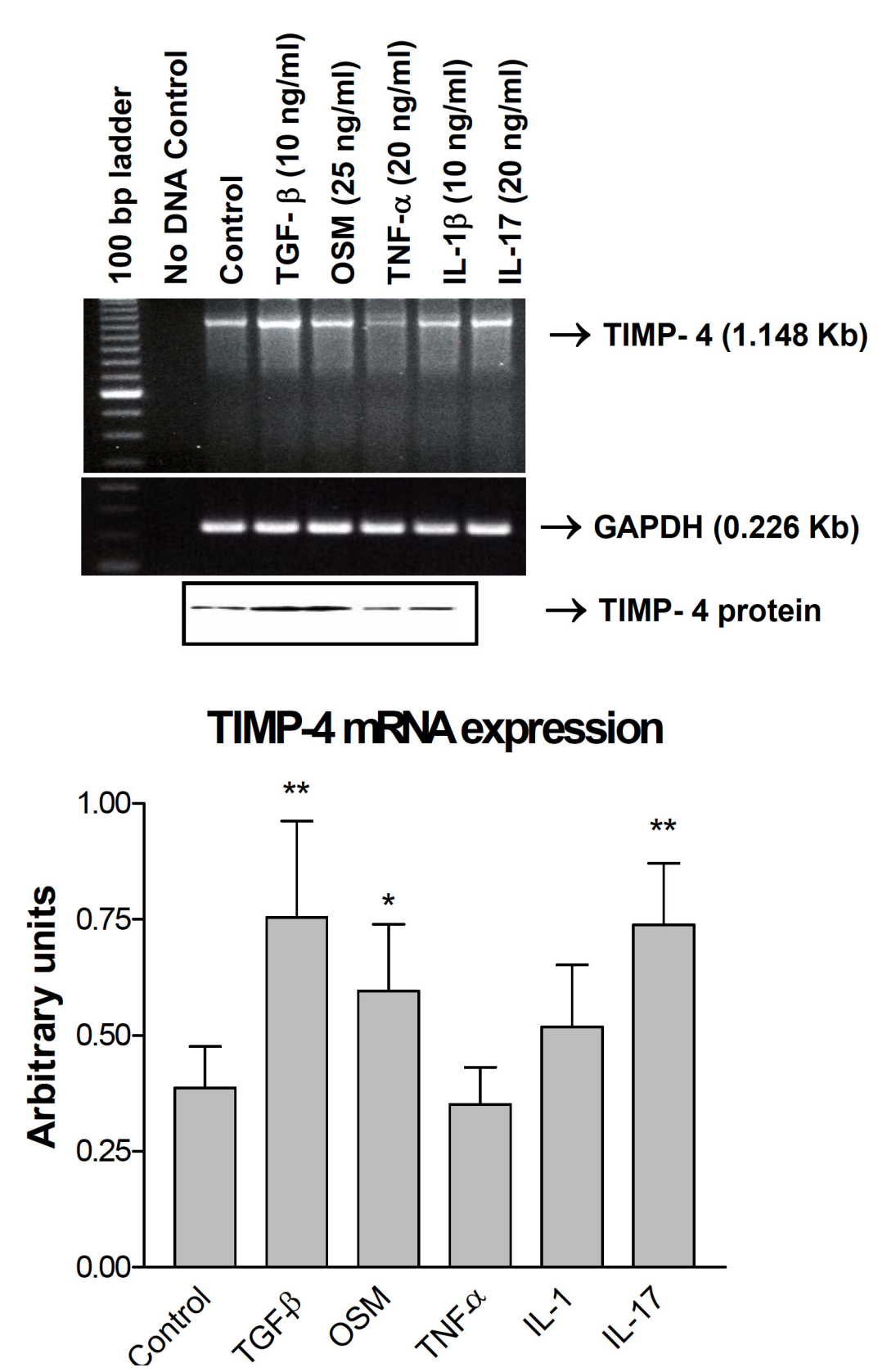

Fig. (3). Impact of TGF- $\beta 1$, OSM, TNF- $\alpha$, IL-1 $\beta$ and IL-17 on TIMP-4 RNA expression in normal human knee primary chondrocytes kept in serum-deficient medium for $24 \mathrm{~h}$, subjected to the indicated treatments and RNA levels analyzed by TIMP-4 and GAPDH RT-PCR. The results are cumulative representative of three independent experiments. On the bottom panel, quantitative analysis of TIMP-4 versus GAPDH RNA is shown: $\mathrm{p}<0.01$ Control versus TGF- $\beta$ and IL-17; ** $\mathrm{p}<0.05$ Control versus OSM*. Whiskers in the graph represent means \pm SEM. TIMP-4 protein levels (except IL-17, not determined) measured by Western blot analysis are also shown.

Constitutive TIMP-4 expression levels in non-OA synovial tissues may be related to its important role and persistent requirement in physiologic situations such as protection of synovial ECM integrity, anti-angiogenic, growth-promoting or anti-apoptotic activities [1]. TIMP-4 gene delivery is known to stimulate growth of breast cancer cells [21].

Human femoral head normal and OA chondrocytes clearly synthesize TIMP-4 mRNA under ex vivo conditions suggesting its physiological roles in maintenance of balance with MMPs to protect its matrix. These results represent mainly older patients as tissues from young patients were not available. The reasons for its constitutive expression in normal and variable expression in knee OA chondrocytes are unknown. Some OA patients may have decreased expression of TIMP4 as reported for the end-stage hip OA cartilage [22]. Whether TIMP-4 deficiency contributes to OA pathogenesis, remains to be studied further. In one report, TIMP-4 RNA reduction in periprosthetic interface tissue has been associated with loose artificial hip prosthesis [23]. In contrast with the increased TIMP-1, TIMP-2 and TIMP-3, TIMP-4 RNA levels 


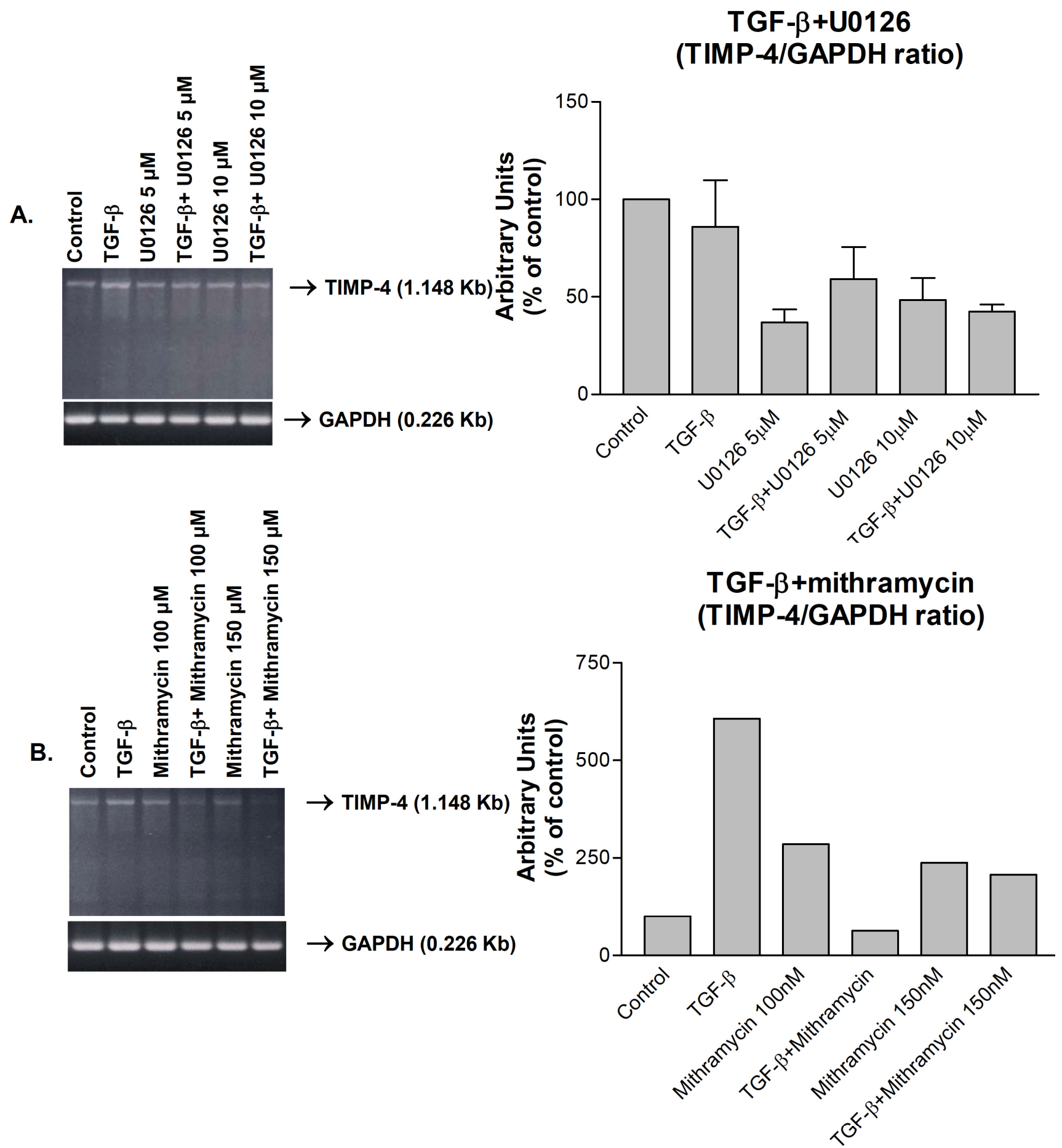

Fig. (4). Down-regulation of TGF- $\beta 1$-induced TIMP-4 RNA expression by (A) ERK (U0126) and (B) Sp1 (mithramycin) inhibitors as analyzed by RT-PCR. Human knee chondrocytes were kept in serum-deficient medium for $24 \mathrm{~h}$, subjected to the indicated treatments for 24 $\mathrm{h}$ and mRNA levels analyzed by TIMP-4 and GAPDH RT-PCR. The right panels are cumulative graphic depictions of mean TIMP4/GAPDH ratios of three (A) or two (B) separate experiments.

were decreased during early inflammatory phase of healing rabbit ligaments [24]. Single nucleotide polymorphism at the 3'-untranslanted region of TIMP-4 gene has also been associated with susceptibility of Korean patients to OA [25].

Arthritis-associated cytokines differentially regulate TIMP4 gene expression in knee chondrocytes. Induction of TIMP-4 by TGF- $\beta 1$, a major stimulant of cartilage matrix synthesis and an antiapoptotic factor in synovial fibroblasts [26] suggests its role in cartilage remodeling and repair as observed during OA pathogenesis. TGF- $\beta 1$ and OSM are also known to upregulate TIMP-1 and TIMP-3 in chondrocytes [17, 27] and could be responsible for the observed TIMP-4 increase in vivo. The overall mild cytokine effect in normal chondrocytes may be due to constitutive and elevated basal TIMP-4 mRNA expression. 
In summary, previously undocumented increase of TIMP-4 in human knee synovium and expression in primary hip and knee chondrocytes was demonstrated. TIMP-4 was differentially induced by arthritis-associated cytokines. In vivo increase may be due to its induction by TGF- $\beta 1$, OSM and IL-17. TGF- $\beta 1$ induces TIMP-4 gene expression partly through ERK and Sp1 pathways. Due to multiple activities of TIMPs in other tissues, additional studies are needed to define TIMP-4 regulation and functions in joints and its potential for inhibiting cartilage and bone resorption [28].

\section{ACKNOWLEDGEMENTS}

This work was supported by the Canadian Institutes of Health Research (CIHR) grants. MZ is a member of the Canadian Arthritis Network (CAN). We thank Drs Julio Fernandes and Nicolas Duval for tissues.

\section{CONFLICT OF INTEREST}

None declared.

\section{REFERENCES}

[1] Baker AH, Edwards DR, Murphy G. Metalloproteinase inhibitors: biological actions and therapeutic opportunities. J Cell Sci 2002; 115: 3719-27.

[2] Fernandez CA, Moses MA. Modulation of angiogenesis by tissue inhibitor of metalloproteinase-4. Biochem Biophys Res Commun 2006; 345: 523-9.

[3] Mohammed FF, Smookler DS, Khokha R. Metalloproteinases, inflammation, and rheumatoid arthritis. Ann Rheum Dis 2003; 62(Suppl 2): ii43-7.

[4] van der Laan WH, Quax PH, Seemayer CA, et al. Cartilage degradation and invasion by rheumatoid synovial fibroblasts is inhibited by gene transfer of TIMP-1 and TIMP-3. Gene Ther 2003; 10: 234-42.

[5] Greene J, Wang M, Liu YE, et al. Molecular cloning and characterization of human tissue inhibitor of metalloproteinase 4. J Biol Chem 1996; 271: 30375-80.

[6] Stratmann B, Farr M, Tschesche H. Characterization of Cterminally truncated human tissue inhibitor of metalloproteinases-4 expressed in Pichia pastoris. Biol Chem 2001; 382: 987-91.

[7] English JL, Kassiri Z, Koskivirta I, et al. Individual timp deficiencies differentially impact pro-MMP-2 activation. J Biol Chem 2006; 281: 10337-46.

[8] Su S, Grover J, Roughley PJ, et al. Expression of the tissue inhibitor of metalloproteinases (TIMP) gene family in normal and osteoarthritic joints. Rheumatol Int 1999; 18: 183-91.

[9] Celiker MY, Ramamurthy N, Xu JW, et al. Inhibition of adjuvantinduced arthritis by systemic tissue inhibitor of metalloproteinases 4 gene delivery. Arthritis Rheum 2002; 46: 3361-8.

[10] Ramamurthy NS, Greenwald RA, Celiker MY, Shi EY. Experimental arthritis in rats induces biomarkers of periodontitis which are ameliorated by gene therapy with tissue inhibitor of matrix metalloproteinases. J Periodontol 2005; 76: 229-33.

[11] Aicher WK, Alexander D, Haas C, et al. Transcription factor early growth response 1 activity up-regulates expression of tissue inhibitor of metalloproteinases 1 in human synovial fibroblasts. Arthritis Rheum 2003; 48: 348-59.
[12] Huang W, Li WQ, Dehnade F, Zafarullah M. Tissue inhibitor of metalloproteinases-4 (TIMP-4) gene expression is increased in human osteoarthritic femoral head cartilage. J Cell Biochem 2002; 85: 295-303.

[13] Huber LC, Distler O, Tarner I, et al. Synovial fibroblasts: key players in rheumatoid arthritis. Rheumatology (Oxford) 2006; 45: 669-75.

[14] Mor A, Abramson SB, Pillinger MH. The fibroblast-like synovial cell in rheumatoid arthritis: a key player in inflammation and joint destruction. Clin Immunol 2005; 115: 118-28.

[15] Chomczynski P, Sacchi N. Single-step method of RNA isolation by acid guanidinium thiocyanate-phenol-chloroform extraction. Anal Biochem 1987; 162: 156-9.

[16] Goldring SR, Goldring MB. The role of cytokines in cartilage matrix degeneration in osteoarthritis. Clin Orthop Relat Res 2004; 427(Suppl): S27-S36.

[17] Qureshi HY, Sylvester J, El Mabrouk M, Zafarullah M. TGF-betainduced expression of tissue inhibitor of metalloproteinases-3 gene in chondrocytes is mediated by extracellular signal-regulated kinase pathway and Sp1 transcription factor. J Cell Physiol 2005; 203: 345-52.

[18] Yuan GH, Tanaka M, Masuko-Hongo K, et al. Characterization of cells from pannus-like tissue over articular cartilage of advanced osteoarthritis. Osteoarthr Cartil 2004; 12: 38-45.

[19] Saito I, Koshino T, Nakashima K, Uesugi M, Saito T. Increased cellular infiltrate in inflammatory synovia of osteoarthritic knees. Osteoarthr Cartil 2002; 10: 156-62.

[20] Koskivirta I, Rahkonen O, Mayranpaa M, et al. Tissue inhibitor of metalloproteinases 4 (TIMP4) is involved in inflammatory processes of human cardiovascular pathology. Histochem Cell Biol 2006; 126: 335-42

[21] Jiang Y, Wang M, Celiker MY, et al. Stimulation of mammary tumorigenesis by systemic tissue inhibitor of matrix metalloproteinase 4 gene delivery. Cancer Res 2001; 61: 2365-70.

[22] Kevorkian L, Young DA, Darrah C, et al. Expression profiling of metalloproteinases and their inhibitors in cartilage. Arthritis Rheum 2004; 50: 131-41.

[23] Sasaki K, Takagi M, Mandelin J, et al. Quantitative analysis of mRNA expression of TIMPs in the periprosthetic interface tissue of loose hips by real-time PCR system. J Biomed Mater Res 2001; 58: 605-12.

[24] Reno C, Boykiw R, Martinez ML, Hart DA. Temporal alterations in mRNA levels for proteinases and inhibitors and their potential regulators in the healing medial collateral ligament. Biochem Biophys Res Commun 1998; 252: 757-63.

[25] Lee HJ, Lee GH, Nah S, et al. Association of TIMP-4 gene polymorphism with the risk of osteoarthritis in the Korean population. Rheumatol Int 2008; 28: 845-50.

[26] Kawakami A, Urayama S, Yamasaki S, et al. Anti-apoptogenic function of TGFbetal for human synovial cells: TGFbetal protects cultured synovial cells from mitochondrial perturbation induced by several apoptogenic stimuli. Ann Rheum Dis 2004; 63: 95-7.

[27] Li WQ, Zafarullah M. Oncostatin M up-regulates tissue inhibitor of metalloproteinases-3 gene expression in articular chondrocytes via de novo transcription, protein synthesis, and tyrosine kinase- and mitogen-activated protein kinase-dependent mechanisms. J Immunol 1998; 161: 5000-7.

[28] Murphy G, Lee MH. What are the roles of metalloproteinases in cartilage and bone damage? Ann Rheum Dis 2005; 64(Suppl 4): iv44-7. 